\title{
Is the routine use of bevacizumab in the treatment of women with advanced or recurrent cancer of the cervix sustainable?
}

This article was published in the following Dove Press journal:

ClinicoEconomics and Outcomes Research

21 June 2016

Number of times this article has been viewed

\section{Natalie Klag \\ Adam C Walter \\ Kristen M Sheely \\ Kelly J Manahan \\ John P Geisler}

Division of Gynecologic Oncology,

Cancer Treatment Centers of

America Newnan, Georgia, USA
Correspondence: John P Geisler

Division of Gynecologic Oncology,

Cancer Treatment Centers of America

Newnan, 600 Celebrate Life Parkway

Newnan, 30265, Georgia, USA

Fax + I 4044202498

Email wlvrnhwky@me.com
Background: New chemotherapy combinations are being tested for the treatment of women with advanced, persistent or recurrent cervical cancer. We sought to evaluate the cost effectiveness of some newer combination therapies in cervical cancer.

Patients and methods: A cost effectiveness decision model was used to analyze Gynecologic Oncology Group 240. All regimens were modeled for seven cycles. The regimens studied are as follows: regimen 1, cisplatin/paclitaxel $(\mathrm{CP})$; regimen 2, $\mathrm{CP}$ with bevacizumab $(\mathrm{CP}+\mathrm{B})$; regimen 3, paclitaxel/topotecan (PT); and regimen 4, PT with bevacizumab (PT+B). Overall survival, cost, and complications were studied. Sensitivity analyses were performed.

Results: Mean chemotherapy costs over mean total costs for seven cycles of each follows: CP \$571/\$32,966; CP+B \$61,671/\$96,842; PT \$9,211/\$71,620; and PT+B \$70,312/\$109,211. Incremental cost-effectiveness ratio (ICER) for $\mathrm{CP}+\mathrm{B}$ was $\$ 133,559$ /quality adjusted life year (QALY). ICER for PT+B was \$124,576/QALY. To achieve an incremental ICER for CP+B:CP of $<\$ 50,000 / \mathrm{QALY}$ gained, the mean overall survival has to increase from 1.1 years with $\mathrm{CP}$ to 3.5 years with $\mathrm{CP}+\mathrm{B}$. An ICER $<\$ 50,000 / \mathrm{QALY}$ for the other regimens would take a survival of $>10$ years for PT and 4.1 years for PT $+\mathrm{B}$. Treating 1,000 women with cervical cancer with $\mathrm{CP}+\mathrm{B}$ would cost almost double the cost of treating $>18,000$ women with ovarian cancer annually (carboplatin/paclitaxel).

Conclusion: $\mathrm{CP}$ is the most cost effective regimen. A 12-month increase in overall survival will not even make the newer combinations cost effective. Currently, the use of bevacizumab is not sustainable at today's costs.

Keywords: cervical cancer, chemotherapy, bevacizumab, cost-effectiveness

\section{Introduction}

Health care providers in the US always want to give the latest/greatest therapies to their individual patients. Is this a sustainable model? Many studies have shown that cancer patients are much more likely to declare bankruptcy than patients with other diseases. ${ }^{1}$ Although we may add a few months of progression free survival or even actual survival, the price tag may be so exorbitant that we cause other long-term sideeffects in the family such as debt, bankruptcy, and even depression. ${ }^{2}$ The discussion of finances is ignored by most physicians but is as important as the discussion of the risk and benefits of therapy.

Cervical cancer is related to lower socio-economic status and poor access to preventative health care. ${ }^{3,4}$ A study from Belgium demonstrated that the average cost of treating a patient with early stage disease was $>\$ 13,000 .^{5}$ This amount increases remarkably if patients no longer have early stage cancer. 
Gynecologic Oncology Group (GOG) 204 was created to look at the role of cisplatin doublets in the care of these women. ${ }^{6}$ This study found that the overall survival, progression free survival, and relative risk all favored the use of cisplatin/paclitaxel (CP) for this population. Thus, CP was established to be the standard of care for this population. GOG 240 compared the new standard with or without the addition of bevacizumab (B) to the doublet of paclitaxel/ topotecan $(\mathrm{PT})$ with or without B $(\mathrm{PT}$ or $\mathrm{PT}+\mathrm{B}){ }^{7}$

We sought to evaluate the cost effectiveness of combination therapies from GOG 240 data that were released at the 2013 American Society of Clinical Oncology meeting. ${ }^{7}$

\section{Materials and methods}

Costs and outcomes of treating women with advanced, recurrent or persistent squamous cell carcinoma of the cervix were modeled. Regimens studied were: $\mathrm{CP}, \mathrm{CP}$ with $\mathrm{B}(\mathrm{CP}+\mathrm{B})$, $\mathrm{PT}$, or PT+B (Figure 1). No access to results from GOG 240 beyond what was published in the reference was available. All patients modeled were treated with seven cycles of chemotherapy. The average patient was assumed to be a 65 -year old (US Medicare coverage) with a body surface area of 2 $\mathrm{m}^{2}$, height of $165 \mathrm{~cm}$, weight of $100 \mathrm{~kg}$, and a creatinine of $0.8 \mathrm{mg} / \mathrm{dL}$ (Cockcroft and Gault actual weight).
The overall survival for the $\mathrm{CP}$ regimen varied quite a bit from GOG 169 to GOG 204 in a similar population (9.7 months to 13 months). ${ }^{6,8}$ Complications, recurrence data, and available survival data were derived from the results of GOG 240 with the topotecan arm supplemented by further data. ${ }^{7,9}$ We did not adjust complication, recurrence, or survival rates for age, and we assumed that experiencing a grade three or worse complication did not affect recurrence or survival rates. Utility values were estimated from the data in the literature. ${ }^{10,11}$

Estimated complication costs were based on 2012 Medicare costs (average sale price January 1, 2012 - March 31, 2012 ) as well as published figures. ${ }^{12,13}$ For values not readily found in the literature, patient reimbursements from Center for Medicare/Medicaid Services were examined for the specific problems. The values used in the base case, as well as the sensitivity analysis ranges, are shown in Table 1.

Values were varied widely in sensitivity analysis to determine the effect on results. One-way sensitivity analysis was performed. Incremental cost-effectiveness ratio (ICER) was measured as cost per quality adjusted life year (QALY) survival, calculated by dividing the difference in cost between the strategies by the difference in survival among the strategic. A willingness to pay threshold (WTP)

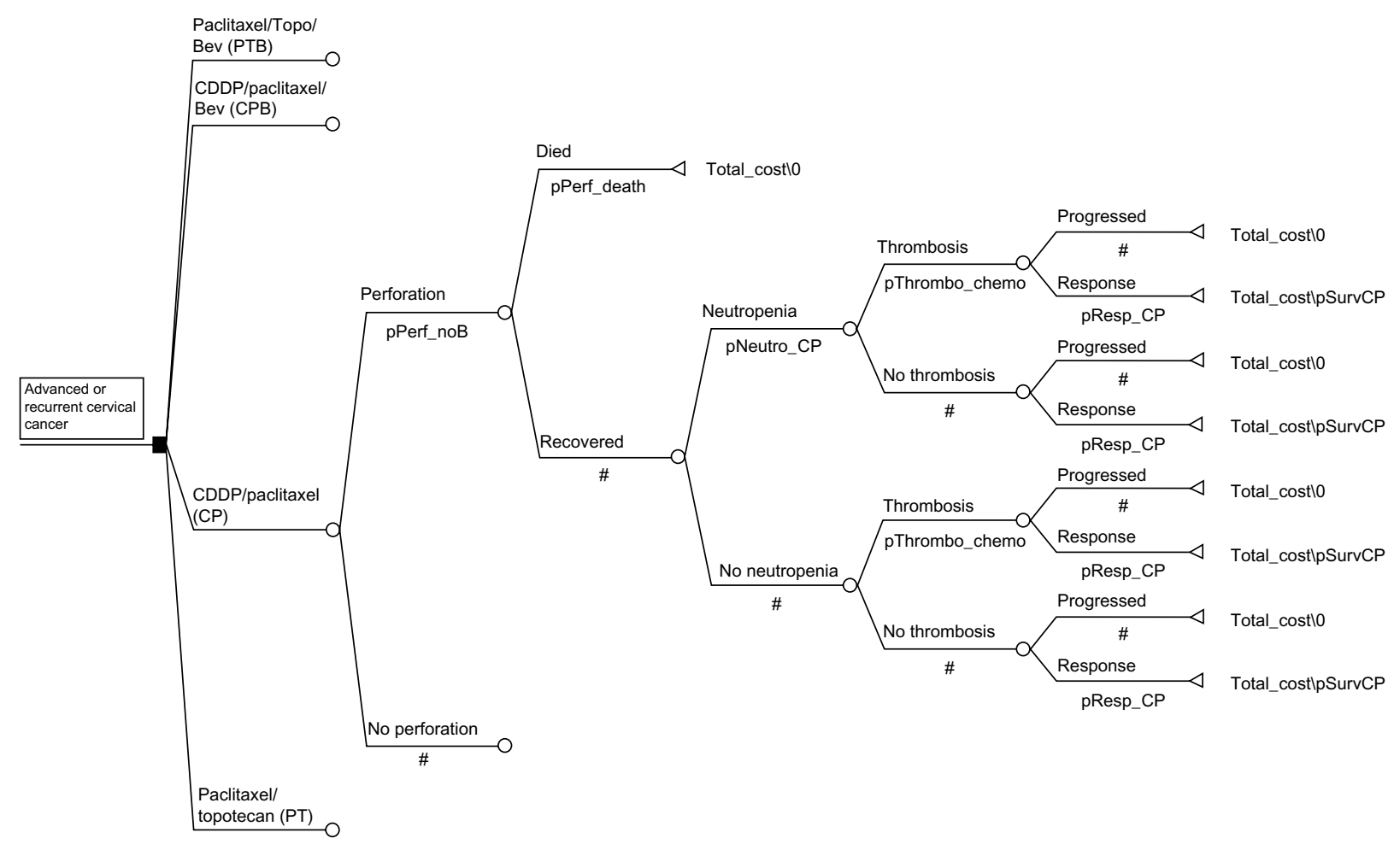

Figure I Decision tree outlining the major decision points in the analysis.

Note: Regimens are defined in the image $100-p=\#$.

Abbreviations: Bev, bevacizumab; CDDP, cisplatin; Perf, perforation; Neutro, neutropenia; Thrombo, thrombosis; chemo, chemotherapy; Resp, Response; Surv, survival; CP, cisplatin/paclitaxel; pPerf_noB, \% perforated without bevacizumab; p, \% perforated. 
Table I Mean survival by chemotherapy

\begin{tabular}{lll}
\hline Treatment & $\begin{array}{l}\text { Mean survival } \\
\text { (years) }\end{array}$ & Reference \\
\hline Cisplatin/paclitaxel (CP) & 1.1 & 7 \\
Cisplatin/paclitaxel/bevacizumab (CP+B) & 1.35 & 7 \\
Paclitaxel/topotecan (PT) & 1.25 & 9 \\
Paclitaxel/topotecan/bevacizumab (PT+B) & 1.56 & 7,9 \\
\hline
\end{tabular}

was based on published literature. An amount of $\$ 50,000$ / QALY was used.

\section{Results}

Although survival varied significantly among GOG 169, 179, and 204, the survival from GOG 204 for CP was used. ${ }^{6,8,14}$ Table 1 lists the mean survivals used in the cost effectiveness analysis. Figure 2 is the cost effectiveness analysis diagram at baseline costs and known survivals. As can be seen, none of the regimens are dominated, so there is potential for each regimen to become a cost-effective alternative. However, the cost frontier from $\mathrm{CP}$ to $\mathrm{PT}+\mathrm{B}$ is steep showing that the ICERs will be high.

Table 2 has two major parts. Column 2 is the actual chemotherapy cost for each of the five chemo regimes studied. As can be seen, the costs vary widely from $\$ 571$ for seven cycles of cisplatin to $\$ 70,312$ for seven cycles of PT $+\mathrm{B}$. Column three includes all direct and indirect costs for seven cycles used in the model (chemotherapy costs, infusion costs, complication rates and costs). Hence, again there is a wide range of costs starting with $\mathrm{CP}$ at $\$ 32,966$ and extending to $\mathrm{PT}+\mathrm{B}$ at $\$ 109,211$. As can be seen from the comparison of columns two and three, changes in cost stem from both the medications (direct costs) and the complications (indirect costs).

The ICER for CP+B was $\$ 133,559 / \mathrm{QALY}$. The ICER for PT+B was \$124,576/QALY and the ICER for PT was $\$ 511,947 /$ QALY. All of these are significantly above a WTP of $\$ 50,000 /$ QALY..$^{15}$

The exact number of patients with cervical cancer annually is unknown. An analysis of cost can be estimated by looking at 1,000 women requiring treatment for this disease annually. Figure 3 compares the cost of treating 1,000 women with this disease by each of the GOG 240 regimens. Figure 4, compares the cost of treating 1,000 women with cervical cancer with $\mathrm{CP}+\mathrm{B}$ versus treating all of the women requiring chemotherapy after surgery for ovarian cancer annually (18,598 women).${ }^{16}$ As seen in Figure 4, treating 1,000 women with $\mathrm{CP}+\mathrm{B}$ for cervical cancer costs $\sim 67 \%$ more than treating over 18,000 women with first-line chemotherapy (carboplatin and paclitaxel) for ovarian cancer.

\section{Cost effectiveness analysis}

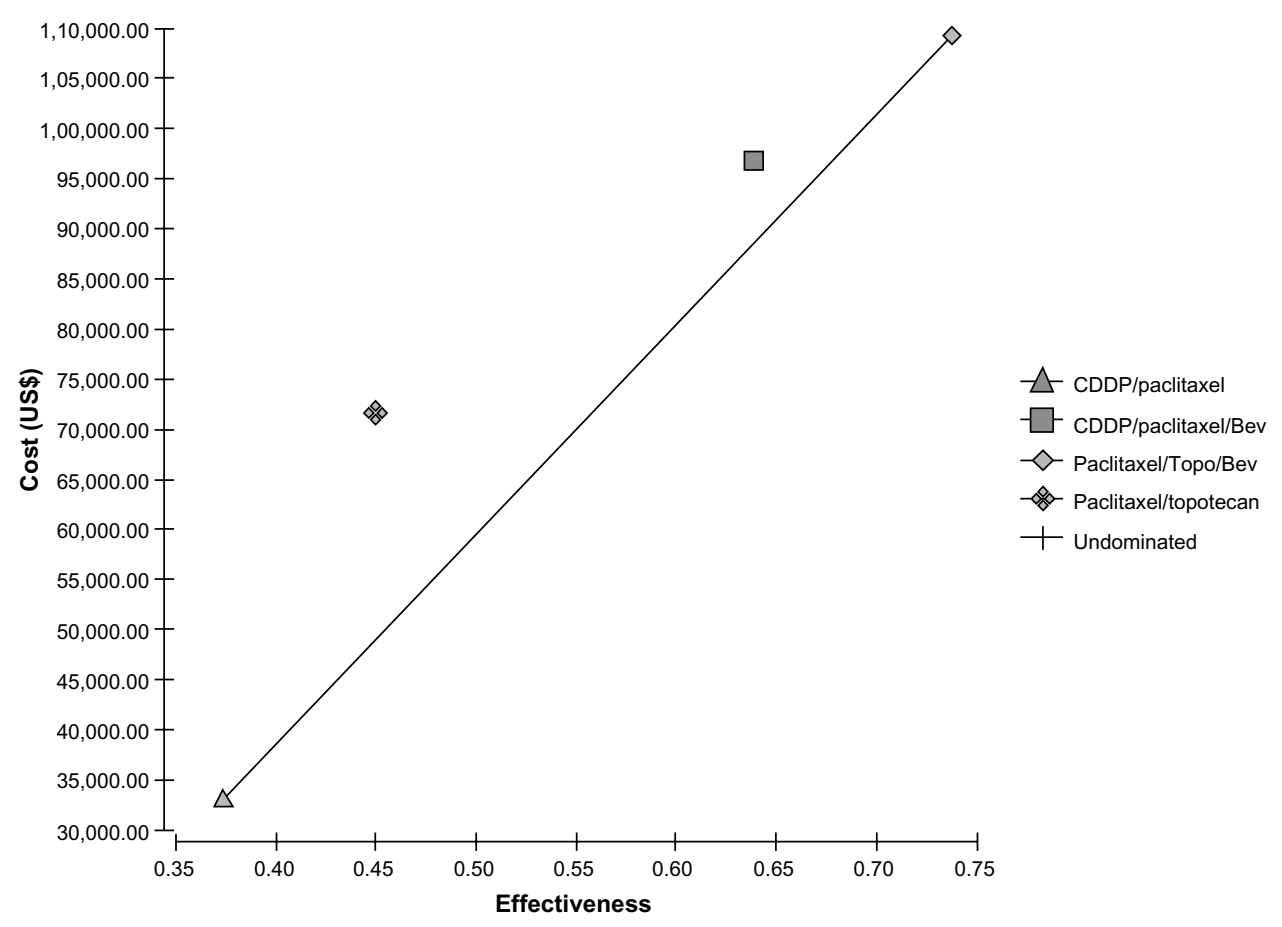

Figure 2 Cost effectiveness diagram with cost on the vertical axis in dollars and relative effectiveness on the horizontal axis.

Note: The shape legends are contained on the figure.

Abbreviations: CDDP, cisplatin; Bev, bevacizumab; Topo, topotecan. 
Table 2 Incremental cost effectiveness ratio by quality adjusted life year

\begin{tabular}{lllll}
\hline Treatment & $\begin{array}{l}\text { Cost of medications } \\
\text { for seven cycles }\end{array}$ & $\begin{array}{l}\text { Mean total costs } \\
\text { for seven cycles (US\$) }\end{array}$ & ICER & Reference \\
\hline CP & $\$ 571$ & $\$ 32,966$ & - & 12,17 \\
CP+B & $\$ 61,671$ & $\$ 96,842$ & $\$ 133,559 / Q A L Y$ & 12,17 \\
PT & $\$ 9,211$ & $\$ 71,620$ & $\$ 511,947 / Q A L Y$ & 12,17 \\
PT+B & $\$ 70,312$ & $\$ 109,211$ & $\$ 124,576 / Q A L Y$ & 12,17 \\
\hline
\end{tabular}

Abbreviations: CP, cisplatin/paclitaxel; CP+B, cisplatin/paclitaxel/bevacizumab; PT, paclitaxel/topotecan; PT+B, paclitaxel/topotecan/bevacizumab; ICER, incremental costeffectiveness ratio; QALY, quality adjusted life year.

\section{Discussion}

Over the past decade the standard of care for this unfortunate patient population has changed from cisplatin (6.5-8.8 months average overall survival), to cisplatin/topotecan (9.4 months average overall survival) to CP (12.9 months average overall survival). Therefore, CP chemotherapy is now commonly used for the treatment of advanced cancer of the cervix because of GOG 204. ${ }^{6}$ Geisler et al previously demonstrated that $\mathrm{CP}$ was an acceptable alternative to cisplatin alone for women with this advanced disease. ${ }^{17}$ The other doublets, although more effective than cisplatin alone, were less effective and more expensive than CP. This fact strengthens the use of the CP regimen as standard of care. This result brought forth the question about the addition of bevacizumab to $\mathrm{CP}$. Thus, GOG 240 was created. With the expense of bevacizumab, does the added survival found in the bevacizumab arms make it cost effective and sustainable? While getting a 4-month increase in overall survival in GOG 240 is statistically significant, it comes at the addition of huge costs. Figure 4 shows that it would cost more to treat 1,000 women with advanced or recurrent cervical cancer than to treat 18,000

\section{Comparison of amount spent to treat 1,000 women}

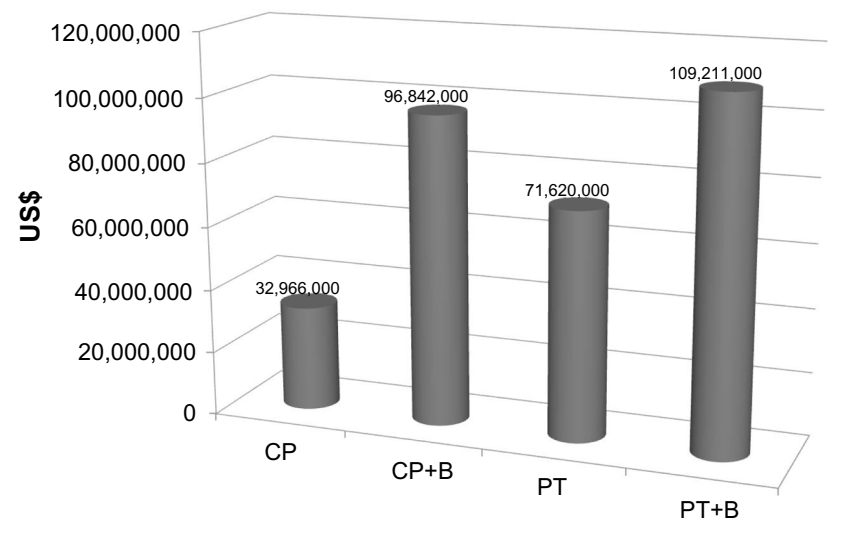

Figure 3 Comparison of GOG 240 regimens when treating I,000 women. Note: Costs are on the diagrams vertical axis.

Abbreviations: GOG, Gynecologic Oncology Group; CP, cisplatin/paclitaxel; $\mathrm{CP}+\mathrm{B}$, cisplatin/paclitaxel/bevacizumab; PT, paclitaxel/topotecan; PT+B, paclitaxel/ topotecan/bevacizumab. women with newly diagnosed ovarian cancer. The goal of cost effectiveness analysis is to determine when a paradigm shift should occur because a new regimen is more efficient and has an acceptable cost. Although economically this concept is easy to understand, medically it is not easily understood or accepted. Doctors want the latest and greatest treatments for their patients even if the small incremental increase in survival cannot justify an exorbitant price tag.

In the United Kingdom, the National Institute for Health and Clinical Excellence (NICE) approved cisplatin/topotecan for use in a very select sub-population. ${ }^{18}$ This group included women without prior platin-analog exposure. That specific population was not a primary end point in GOG 179. NICE also accessed data from GOG 179 which were not generally available. Despite the acceptance of cisplatin/topotecan (CT) by NICE, the newer data from GOG 204, show that CP, not $\mathrm{CT}$, is the standard regimen.

Looking at Tables 1 and 2, one can see that the survival for the arms containing bevacizumab have an increased survival of approximately 4 months. However, the ICER is over $\$ 100,000$ / QALY. In Shiroiwa et al's study from 2010, an acceptable WTP in the US was $\$ 62,500 .{ }^{15}$ This estimate is far below the ICER for the addition of bevacizumab in these patients. To get the ICER down to this study's WTP of \$50,000/QALY, the survival increase would have to go from 4 months to 12 months.

Geisler et al have further demonstrated that if targeted therapies (anti-angiogenesis drugs, tyrosine kinase inhibitors, etc) are to become standard of care over $\mathrm{CP}$, either larger improvements in survival or lower prices $(\$ 100$ s instead of $\$ 1,000$ s or $\$ 10,000$ s) will be necessary. ${ }^{19}$ All physicians want better

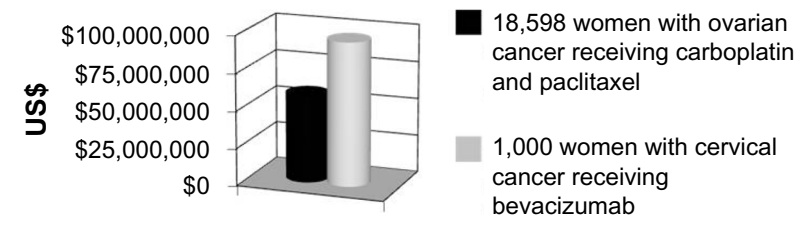

Figure 4 Comparison of treating I,000 women with advanced or recurrent cervical cancer with cisplatin/paclitaxel/bevacizumab to treating 18,598 women with ovarian cancer and carboplatin/paclitaxel after initial debulking surgery. 
survival for their patients, but it has to be sustainable. Most countries, including the US do not have the resources to treat patients regardless of the cost. Rationing health care is not ethical, but neither is spending money on treatments that are not worth the expense. We need to rationally approach changes in standards of care so that we can treat the most patients with the best possible treatments. This fact would make one compliment the authors of GOG 240 for the improvement they found by adding bevacizumab, but recommend holding off changing the standard of care away from $\mathrm{CP}$ until either a regimen with longer survival or much cheaper cost is found. Only cost effective care can be sustainable in a situation in which money is finite.

\section{Disclosure}

The authors have declared no conflicts of interest.

\section{References}

1. Ramsey S, Blough D, Kirchhoff A, et al. Washington State cancer patients found to be at greater risk for bankruptcy than people without a cancer diagnosis. Health Aff (Millwood). 2013;32(6):1143-1152.

2. Amir Z, Wilson K, Hennings J, Young A. The meaning of cancer: implications for family finances and consequent impact on lifestyle, activities, roles and relationships. Psychooncology. 2012;21(11): $1167-1174$

3. Robinson KM, Christensen KB, Ottesen B, KrasnikA. Socio-demographic factors, comorbidity and diagnostic delay among women diagnosed with cervical, endometrial or ovarian cancer. Eur J Cancer Care (Engl). 2011; 20(5):653-661.

4. Drolet M, Boily MC, Greenaway C, et al. Sociodemographic inequalities in sexual activity and cervical cancer screening: implications for the success of human papillomavirus vaccination. Cancer Epidemiol Biomarkers Prev. 2013;22(4):641-652.

5. Annemans L, Remy V, Lamure E, et al. Economic burden associated with the management of cervical cancer, cervical dysplasia and genital warts in Belgium. J Med Econ. 2008;11(1):135-150.

6. Monk BJ, Sill MW, McMeekin DS, et al. Phase III Trial of Four CisplatinContaining Doublet Combinations in Stage IVB, Recurrent, or Persistent Cervical Carcinoma: A Gynecologic Oncology Group Study. J Clin Oncol. 2009;27(28):4649-4655.
7. Tewari K, Sill M, Long HJ, et al. Incorporation of bevacizumab in the treatment of recurrent and metastatic cervical cancer: A phase III randomized trial of the Gynecologic Oncology Group. ASCO 2013. J Clin Oncol. 2013;(Suppl; abstr 3).

8. Moore DH, Blessing JA, McQuellon RP, et al. Phase III Study of Cisplatin With or Without Paclitaxel in Stage IVB, Recurrent, or Persistent Squamous Cell Carcinoma of the Cervix: A Gynecologic Oncology Group Study. J Clin Oncol. 2004;22(15):3113-3119.

9. Tiersten AD, Selleck MJ, Hershman DL, et al. Phase II study of topotecan and paclitaxel for recurrent, persistent, or metastatic cervical carcinoma. Gynecol Oncol. 2004;92(2):635-638.

10. Versteegh MM, Leunis A, Uyl-de Groot CA, Stolk EA. Conditionspecific preference-based measures: benefit or burden? Value Health. 2012;15(3):504-513.

11. Jewell EL, Smrtka M, Broadwater G, et al. Utility Scores and Treatment Preferences for Clinical Early-Stage Cervical Cancer. Value Health. 2011;14(4):582-586.

12. Centers for Medicare and Medicaid Services [homepage on the Internet]. Medicare Part B Drug Average Sales Price Manufacturer reporting of Average Sales Price (ASP) data. Available from: http://www.cms.gov/ Medicare/Medicare-Fee-for-Service-Part-B-Drugs/McrPartBDrugAvgSalesPrice/. Accessed February 24, 2015.

13. Cohn DE, Kim KH, Resnick KE, O’Malley DM, Straughn JM Jr. At what cost does a potential survival advantage of bevacizumab make sense for the primary treatment of ovarian cancer? A cost-effectiveness analysis. J Clin Oncol. 2011;29(10):1247-1251.

14. Long HJ 3rd, Bundy BN, Grendys EC Jr, et al. Randomized Phase III Trial of Cisplatin with or without Topotecan in Carcinoma of the Uterine Cervix: A Gynecologic Oncology Group Study. J Clin Oncol. 2005;23(21):4626-4633.

15. Shiroiwa T, Sung YK, Fukuda T, Lang HC, Bae SC, Tsutani K. International survey on willingness-to-pay (WTP) for one additional QALY gained: what is the threshold of cost effectiveness? Health Econ. 2010;19(4):422-437.

16. Walter AC, Manahan KJ, Geisler JP. Annual cost of bevacizumab in the adjuvant treatment of ovarian cancer to the U.S. Medicare system. Gynecologic Oncology. 2012;125(Suppl 1):S15.

17. Geisler JP, Swathirajan J, Wood KL, Manahan KJ. Treatment of Advanced or Recurrent Cervical Cancer with Cisplatin or Cisplatin Containing Regimens: A Cost Effective Analysis. J Cancer. 2012;3: 454-458.

18. Paton F, Paulden M, Saramago P, et al. Topotecan for the treatment of recurrent stage IB carcinoma of the cervix. Health Technol Assess. 2010;14 Suppl 1:55-62.

19. Geisler JP, Walter AC, Manahan KJ. An economic analysis of new regimens in the treatment of women with advanced or recurrent cervical cancer. Eur Soc Gynecol Oncol - Liverpool, UK: 2013.
ClinicoEconomics and Outcomes Research

\section{Publish your work in this journal}

ClinicoEconomics \& Outcomes Research is an international, peerreviewed open-access journal focusing on Health Technology Assessment, Pharmacoeconomics and Outcomes Research in the areas of diagnosis, medical devices, and clinical, surgical and pharmacological intervention. The economic impact of health policy and health systems

\section{Dovepress}

organization also constitute important areas of coverage. The manuscript management system is completely online and includes a very quick and fair peer-review system, which is all easy to use. Visit http://www.dovepress.com/testimonials.php to read real quotes from published authors. 